\title{
ERIK: an isokinetic exercise device for the lower limbs
}

\author{
Ken'ichi Koyanagi ${ }^{1 *}$, Yoshinori Kimura ${ }^{2}$, Maki Koyanagi ${ }^{3}$, Akio Inoue ${ }^{4}$, Takumi Tamamoto $^{1}$, Kei Sawai ${ }^{1}$, \\ Tatsuo Motoyoshi ${ }^{1}$, Hiroyuki Masuta ${ }^{1}$ and Toru Oshima ${ }^{1}$
}

\begin{abstract}
In the current study, we tested a prototype of an isokinetic exercise device for the lower limbs, named the ERIK. The ERIK enables a type of single-limb squat exercise with a translational load on the swing leg in a closed kinetic chain, putting load on the muscles of the stance leg in the standing position. This training applies load to the gluteal muscles, which is effective for avoiding excessive knee valgus moment, a major factor in anterior cruciate ligament injuries. To enhance the quality of the load, an electro-rheological (ER) fluid brake system is implemented in the ERIK. The ER brake can reversibly control resistive torque with a rapid response. This paper reports a prototype of the device with four training modes, verifying its performance through basic experiments. Although high resistance is created within a wide motion area and requires isokinetic training by controlling the velocity of the trainee's legs, the ERIK has the advantage of a high level of safety because of its passive resistive function.
\end{abstract}

Keywords: 23rd Robotics Symposia, Isokinetic exercise, Lower limb, Closed kinetic chain training, ER fluid

\section{Introduction}

\section{Background and aim}

Anterior cruciate ligament (ACL) injuries are a common knee injury during sporting activities. The number of ACL injuries per year in Japan has not been investigated on a national level, but is estimated to be approximately 4 in 10,000 individuals. In addition, approximately 10,000 ACL reconstructions are performed each year in Japan [1]. Similarly, the number of ACL injuries in the United States is estimated to be approximately 3 in 10,000 individuals per year [2].

In the current study, we tested a prototype of an isokinetic exercise device for the lower limbs. The proposed device involves a type of single-limb squat, which applies a translational load on the swing leg in the closed kinetic chain $(C K C)$ style, placing load by the body weight on the muscles of the stance leg in the standing position. We refer to this training style as a resistive leg reach exercise [3]. This type of training applies load to the

\footnotetext{
*Correspondence: koyanagi@pu-toyama.ac.jp

${ }^{1}$ Faculty of Engineering, Toyama Prefectural University, 5180 Kurokawa, Imizu, Toyama 939-0398, Japan

Full list of author information is available at the end of the article
}

gluteal muscles, and is effective for preventing knee valgus moment, a major factor in ACL injuries. The primary goal of this style of training is to rehabilitate and/ or preserve the ACL, and to provide a useful method for athletic strength training. To enhance the quality of the load used in this type of exercise, we have developed an electro-rheological isokinetic exercise device prototype, called the "ERIK" [4-6]. The ERIK includes an electro-rheological (ER) fluid brake system, which provides apparent viscosity that can be reversibly controlled by varying the applied voltage. In the current study, we tested the ERIK to verify its performance through reproducible experiments using a servomotor, in contrast with previous studies using only a basic control. Moreover, several new training modes were also tested, including the initial resistance mode and the terminal resistance mode.

\section{Training styles}

Strength training styles include an isotonic exercise performed with a constant load, an isometric exercise performed in a constant posture, and an isokinetic exercise performed at a constant angular velocity of the joint. However, because of the requirement of a real-time 
controller to apply resistance, very few commercialized products are available for isokinetic exercise training. Most of the currently available products target only rotational movements of a joint in a sitting position, such as the Cybex [7], HUMAC-NORM [8], and MARES [9] devices. Although a real-time speed control system

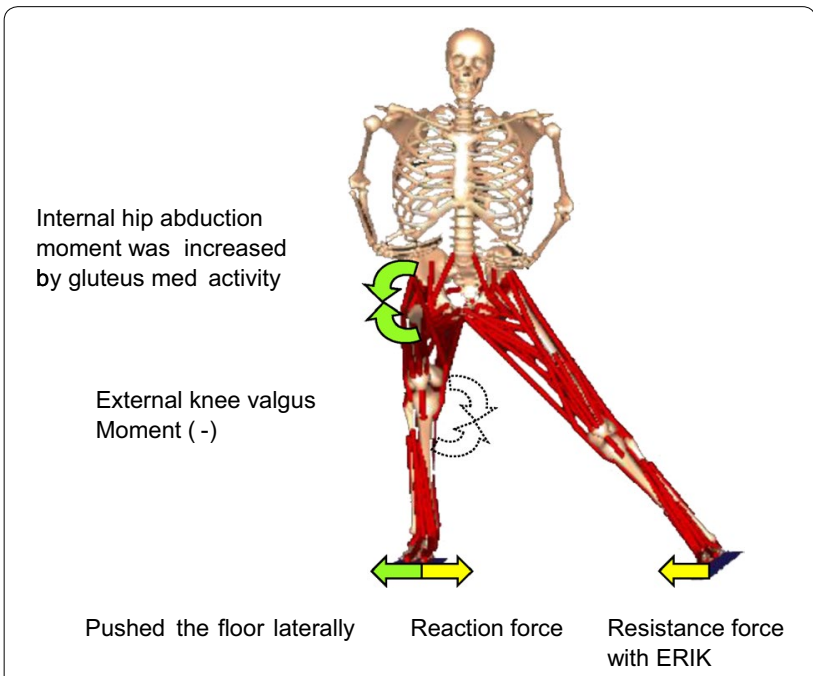

Fig. 1 Schematic image of the resistive leg reach exercise in CKC training style using magneto-rheological fluid was included in a proposed stepper device [10], the equipment enabled limited trainee postures and motion types because of its recumbent design.

Closed kinetic chain training creates a closed-loop linkage with both legs and the floor. Importantly, because this type of exercise decreases the anterior shear and valgus forces on the knee joint, it has a high level of safety. Kimura et al. analyzed CKC training in the standing (loaded) posture for rehabilitation after ACL reconstruction, and applied it clinically to evaluate its safety and effects with a constant resistive force, as shown in Fig. 1, during a single-leg squat using a device with a sliding table and a rubber band $[3,11]$. The single leg squat shown in Fig. 2 includes the right knee bending during the lateral opening motion of the left leg. The reversal motion is conducted during the lift up. However, because the device used a rubber band, the resistant force could not be controlled. Thus, improved training equipment is needed for isokinetic exercise, enabling easy and variable setting of the resistant force to provide acceptable levels of safety and effectiveness.

Isokinetic exercise has a number of benefits: (1) adequate resistance can be loaded for the whole range of motion; (2) the load can be easily tuned in coordination with the reference angular velocity because the joint rotates at a constant velocity; (3) incidental muscle

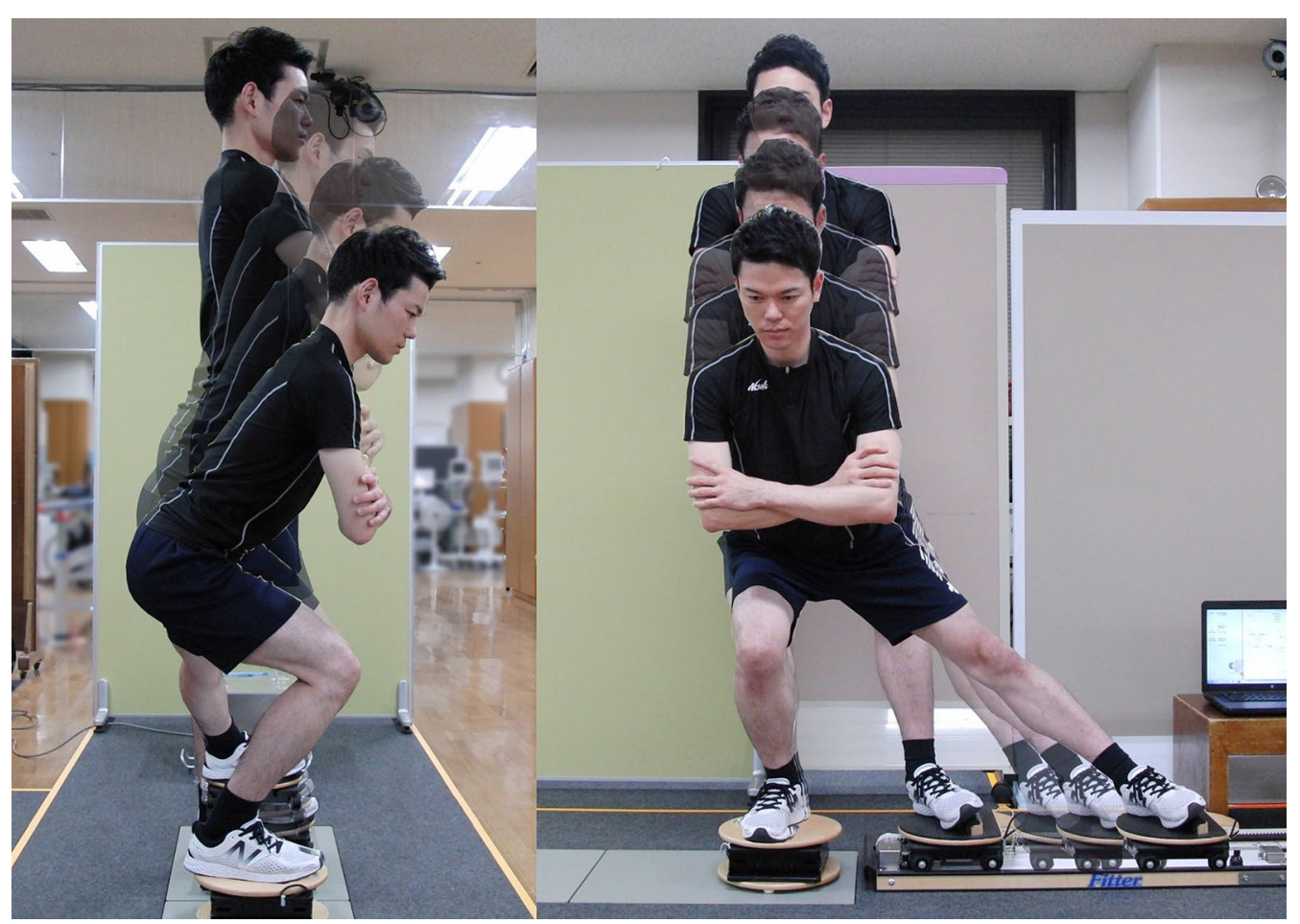

Fig. 2 Strobe of a single leg squat motion 
injuries are unlikely to occur; and (4) quantitative evaluations of clinical tests and the effects of training are available, because the controller included in the training system enables the measurement of joint torque $[12,13]$.

The ERIK has the advantage of a high level of safety in isokinetic exercise, which conventionally requires controllable actuators, such as servomotors. In addition, the ERIK can load higher resistance within a wide motion area compared with conventional equipment. Unlike other devices, the ERIK enables control of the velocity of the leg during translational motion in isokinetic training, such as the open-close leg exercise. The single leg squat using the ERIK provides the constant velocity motion of the sliding leg; therefore the knee joint flexion at a constant velocity as mentioned as the above benefit (2) is not strictly produced. Thus, whether the isokinetic mode of the ERIK has adequate training effectiveness is confirmed in "Experimental verification" section.

Importantly, the ERIK has unique two training modes: the initial resistance mode, in which resistant force is maximal at the initial position of motion and decreases according to the movement distance of the leg, and the terminal resistance mode, in which the resistant force is minimal at the initial position of the leg and increases according to the moving distance (opposite to the the initial resistance mode). Although this type of resistance pattern is the same as that of devices using a rubber band, the ERIK enables easy adjustment of the maximum resistant force. The trainee can choose either of the modes for their particular training purpose.

\section{ERIK: an isokinetic exercise device for the lower limbs in the standing position ER fluid brake}

Particle-type ER fluid is colloidal fluid consisting of suspended particles, and is commonly referred to as ER fluid. The fluid's apparent viscosity increases when an electric field is applied. Thus, ER fluid is suitable as a working fluid in clutch or brake mechanisms for the specific requirements of control systems, possessing a rapid response speed and no hysteresis [14].

Figure 3 shows the basic structure of an ER brake [15] consisting of a fixed cylinder, a rotational cylinder with a driven shaft, and ER fluid filling the inside. Each cylinder can have a multi-cylindrical body, and the two cylinders also serve as a pair of electrodes. When voltage is applied between them, the output component is forced to slow down or halt. The braking torque does not depend on the shear rate (rotational speed), corresponding only to the magnitude of the applied voltage as shown in Fig. 4, especially the range between 60 and $240 \mathrm{~s}^{-1}$ referring the desired velocity in "Experimental verification" section.

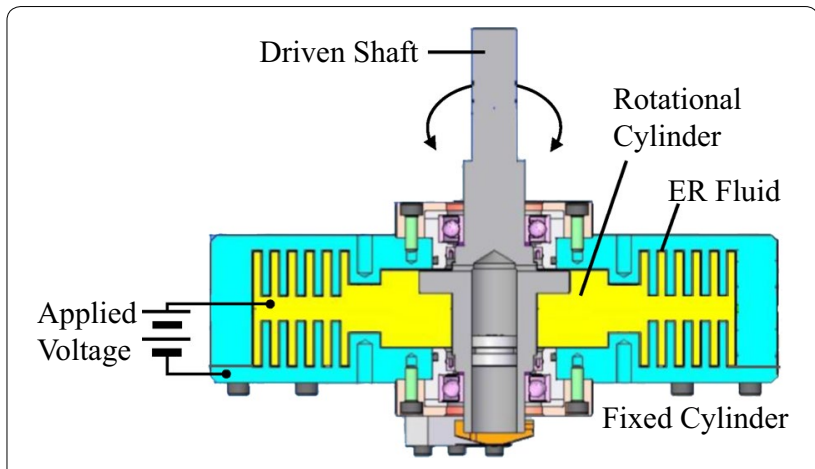

Fig. 3 Sectional view of the ER brake

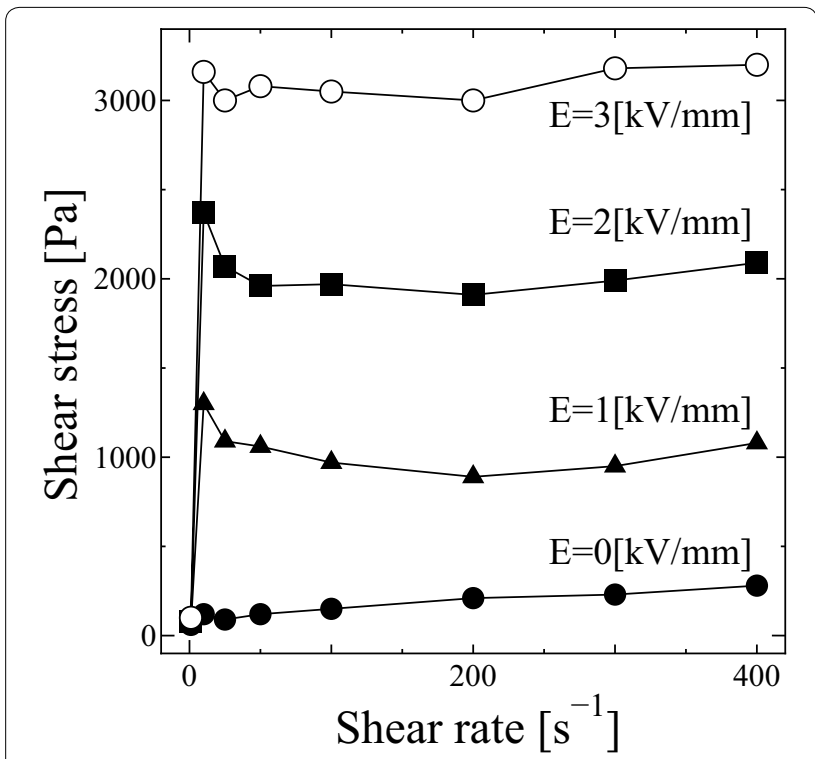

Fig. 4 Shear stress characteristics of the ER fluid

The maximum braking torque depends on the characteristics of the ER fluid used.

\section{Design and prototype of ERIK}

The basic design of the ERIK is shown in Fig. 5. The ERIK prototype is shown in Fig. 6. Its specifications are listed in Table 1. The device has a slidable platform on the top, which is connected to a timing belt. The belt engages with the ER brake via a pulley, transmitting the brake torque to the platform. The position and speed of the platform are calculated from the rotational angle of the brake, which is measured with an encoder. The controller, which runs on a PC, calculates the desired torque according to the situation and outputs this torque value to the ER brake. Quantitative evaluation of the training can be performed with these values because power, work, and other measures 


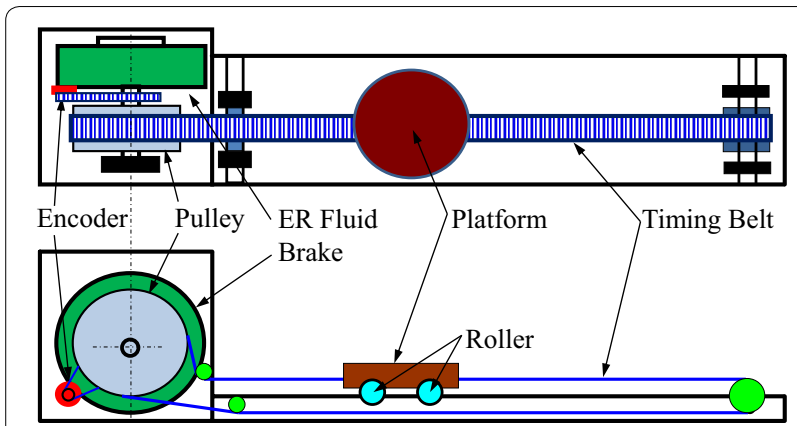

Fig. 5 Schematic image of the isokinetic exercise device for the lower limbs, ERIK

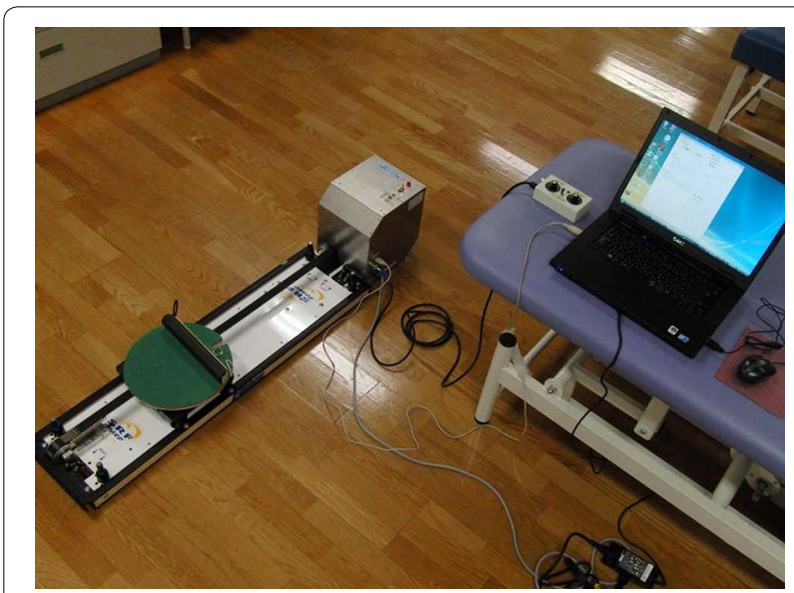

Fig. 6 Prototype of the isokinetic exercise device for the lower limbs, ERIK

Table 1 Specifications of the ERIK prototype

\begin{tabular}{ll}
\hline Parameter & Value \\
\hline Size $(\mathrm{W} \times \mathrm{H} \times \mathrm{L})$ & $0.32 \mathrm{~m} \times 0.26 \mathrm{~m} \times 1.4 \mathrm{~m}$ \\
(From ground level to the platform top) & $0.12 \mathrm{~m}$ \\
Movable range of platform & $0.7 \mathrm{~m}$ \\
Generative maximum force & $\sim 250 \mathrm{~N}$ \\
Desired velocity range & $\leq 1.2 \mathrm{~m} / \mathrm{s}$ \\
\hline
\end{tabular}

can also be calculated from these values. For optimal performance, the resistance must be able to respond rapid in response, exhibit high stability, and have a high torque to volume ratio, making devices using ER fluids preferable. The ERIK cannot move until the trainee moves it themselves, which inherently improves the safety of the device.

Training systems using servomotors, which are in common use and are superior to present ER brakes in terms of cost and availability, can enable isokinetic training.
However, the other training modes of the ERIK produce resistive forces like frictions against the motion of the trainee. Moreover, it is substantially easier to maintain the safety of the trainee with an ER brake system compared with a servomotor system, particularly when an unexpected situation occurs. Magneto-rheological (MR) brakes, which also use a type of functional fluid, have the advantage of a higher torque-weight ratio than ER brakes, because of greater generative shear stress. However, unlike ER brakes with response times of around $5 \mathrm{~ms}$, large torque type MR brakes slow response times of more than $30 \mathrm{~ms}$ in $100 \%$ response, and hysteresis [16].

The goal of exercising with the ERIK device is to strengthen leg squatting on a stage outside of the ERIK. The sliding leg on the platform of the ERIK meets resistance from the brake during squatting, then attempts the open-close exercise in the forward-backward or leftright direction, as shown in Fig. 7. These movements can be used to train muscles of the lower limbs loaded in both the longitudinal and vertical directions. The movable range of the platform is $0.7 \mathrm{~m}$, but this can be restricted further with pins.

A high voltage amplifier and a microcomputer are located inside the main compartment. The ER brake was designed to generate $20 \mathrm{Nm}$ torque at an applied voltage of $1 \mathrm{kV}$ for a restricting force of over $200 \mathrm{~N}$. The high voltage amplifier (ER-1.5k8PX, Chubu-R\&D Co., Japan) can supply a maximum of $1.5 \mathrm{kV}-8 \mathrm{~mA}$ with a response time of approximately $6 \mathrm{~ms}$. The resolution of the encoder (E6B2, OMRON Co., Japan) was increased to $8000 \mathrm{ppr}$ by the belt-pulley transmission mechanism. The microcomputer (iMCs01, iXs Research Co., Japan) transmits the command from the controller (PC), via USB, to the high voltage amplifier after digital to analog conversion. The microcomputer also counts pulses from the encoder, then transmits the information to the PC via USB.

On the controller PC, the software for control and evaluation ran during each sampling time of $10 \mathrm{~ms}$. Although Windows does not ensure real-time responsiveness, the actual sample period was measured using the software. The PC provides a detailed description of the training conditions, a display for training results, and a mechanism for recording the results.

Information about the trainee, the target number of strokes, and the training period is set on the input screen, as shown in Fig. 8. The training mode, the reference value of the training mode, and other details are set on the running screen, as shown in Fig. 9. Values for the resistant force or the desired velocity can be set as constants. The desired velocity of the platform is set to have a maximum value of $1.2 \mathrm{~m} / \mathrm{s}$, which is specified empirically in accord with previous studies $[3,11]$. 


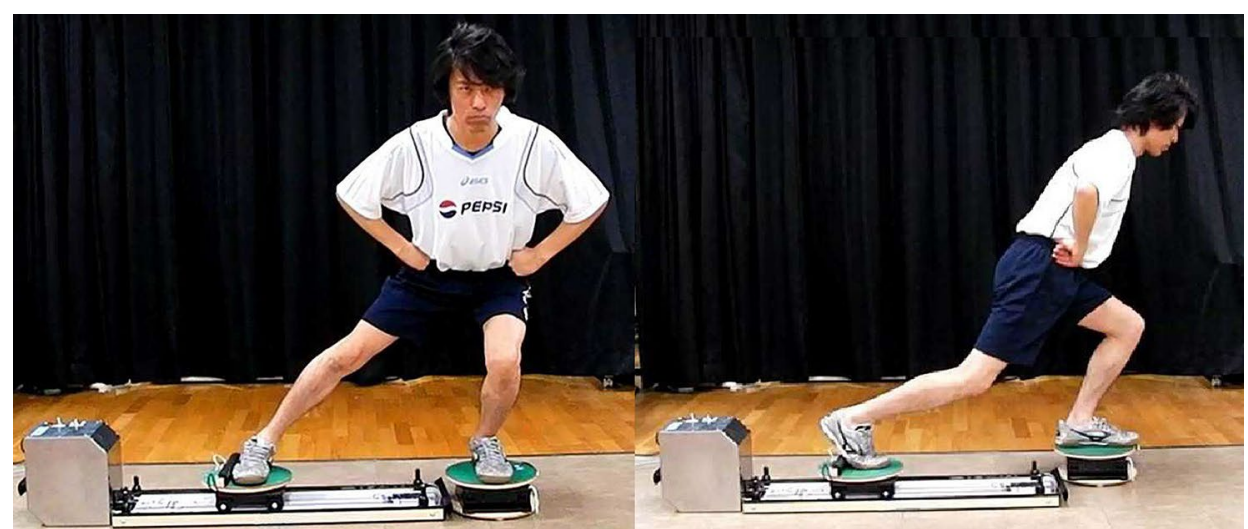

Fig. 7 Examples of practical exercise styles

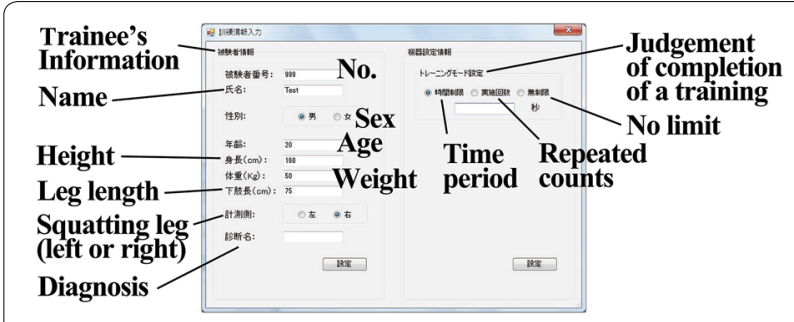

Fig. 8 Input screen for the trainee's data

The running screen also provides trigger information for the training motion and graphs of the speed or the resistant force during training. The results of each training session are recorded in a CSV file for in-depth analysis.
Force characteristics of the prototype

A wire-driven system with a high output motor as shown in Fig. 10 was used to display the force characteristics of the ERIK. The force was measured with a load cell (LURA-500NSA1, Kyowa Electronic Instruments Co., Ltd., Japan) by pulling the platform via the wire by the servomotor (NX1040AS, Oriental Motor Co., Ltd., Japan). The servomotor controlled the rotational velocity, converted to the sliding speed of the platform at $0.20 \mathrm{~m} / \mathrm{s}$, except in the experiments testing the isokinetic exercise mode, in which the servomotor rotates with a constant torque of approximately $15 \mathrm{Nm}$.

The relationship between the energizing voltage $V$ $(\mathrm{kV})$ and resistant force $F(\mathrm{~N})$ of the ERIK prototype was experimentally determined as shown in Fig. 11. Although the shear stress of the ER fluids is known to depend on

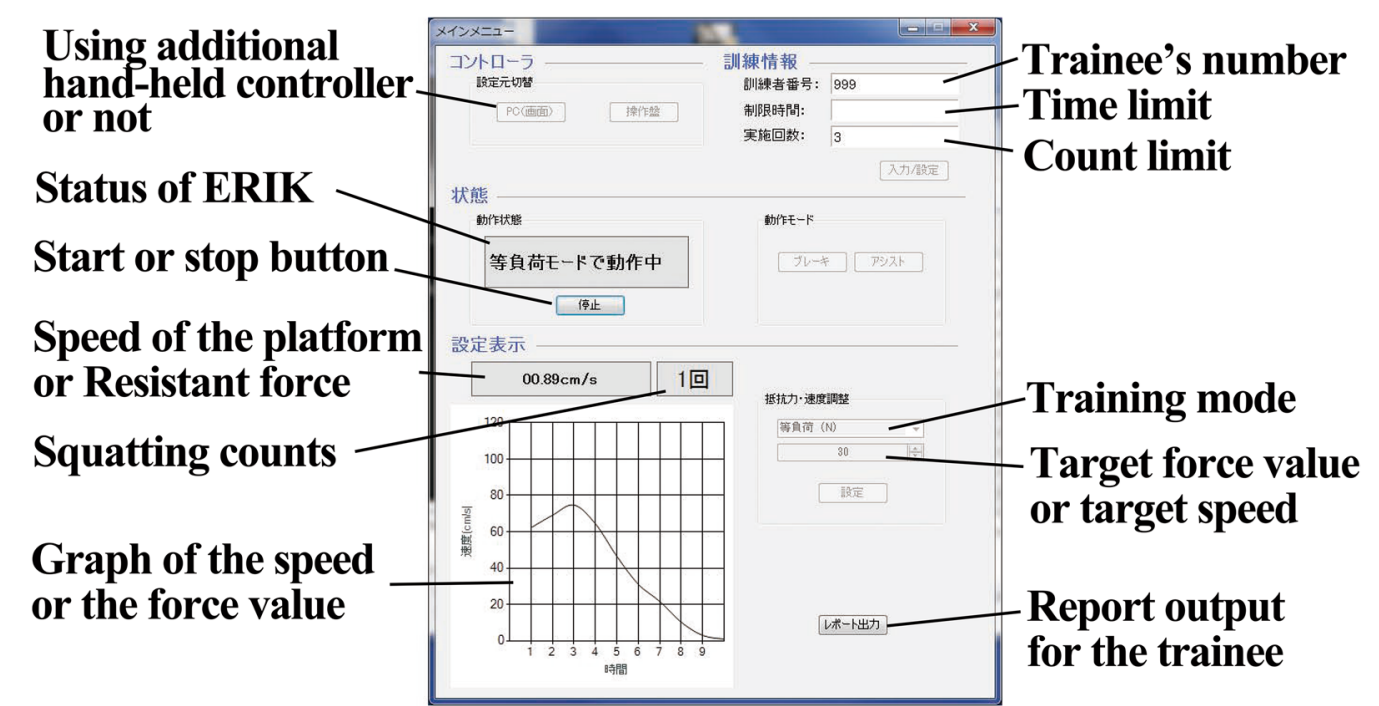

Fig. 9 Screen during exercise. Users can input the training condition on the same screen 


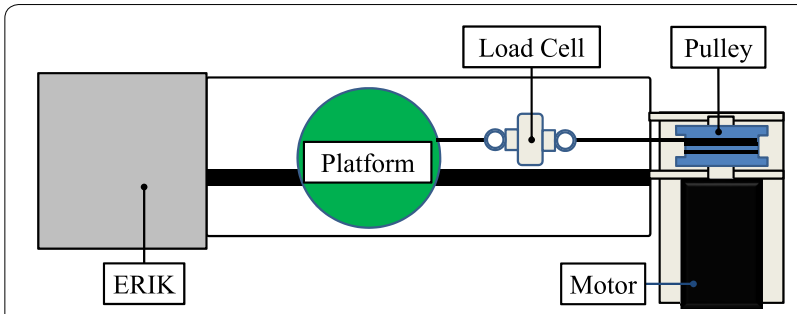

Fig. 10 Experimental system for measuring the braking force of the ERIK

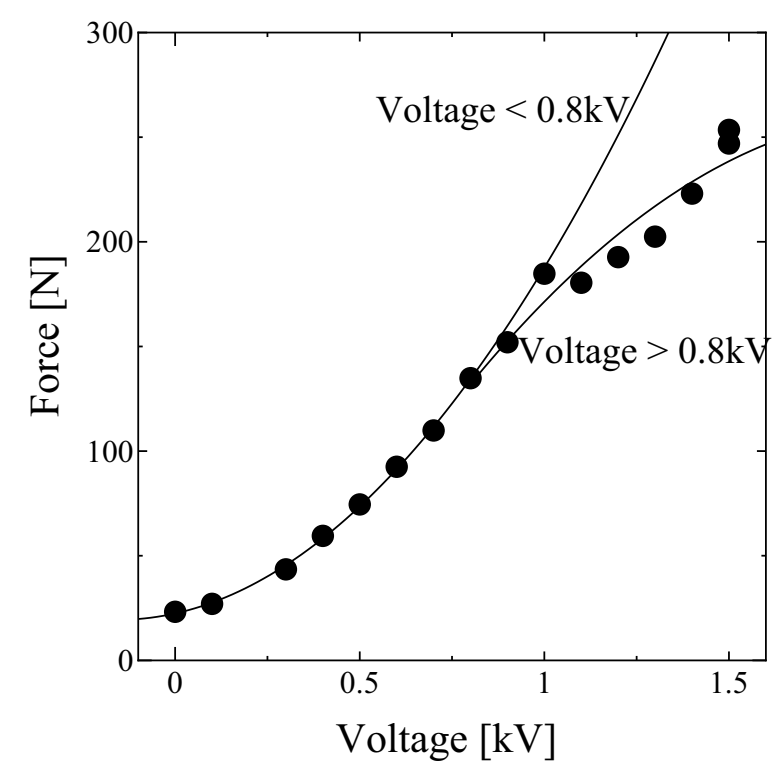

Fig. 11 Voltage and braking force relation of the prototype

the square of the electric field, the experimental result is approximated using the following quadratic equations:

$$
\begin{cases}F=126 V^{2}+39.2 V+22.5 & (V<0.8 \mathrm{kV}) \\ F=-97.3 V^{2}+358 V-89.5 & (V \geq 0.8 \mathrm{kV})\end{cases}
$$

Here, the coefficients of determination are over 0.96 . According to Eq. (1), the ERIK can generate a braking force of almost $250 \mathrm{~N}$ at $1.5 \mathrm{kV}$, which is the maximum voltage for the prototype.

The voltage calculated with the reference force and the inverse function of Eq. (1) was applied to the ER brake to ensure that the ERIK could generate the desired resistive force. The measured values and the line of direct proportion are shown in Fig. 12. When the reference is over $22.5 \mathrm{~N}$, the measured values increase proportionally. The coefficient of determination of the results from the line was 0.998 , confirming that the ERIK was able to represent the reference force.

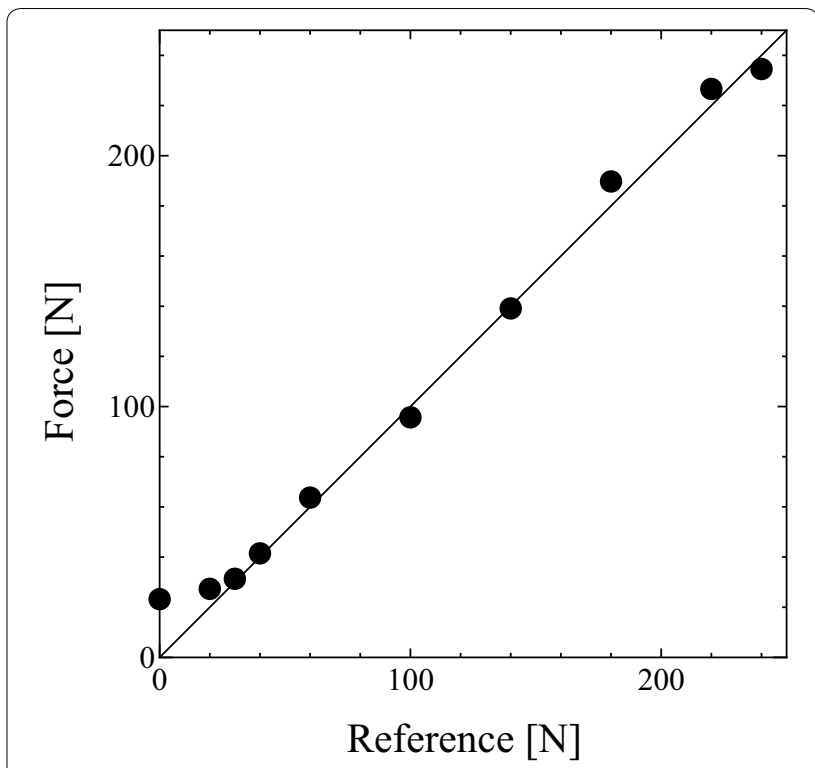

Fig. 12 Reference and measured force relation of the prototype

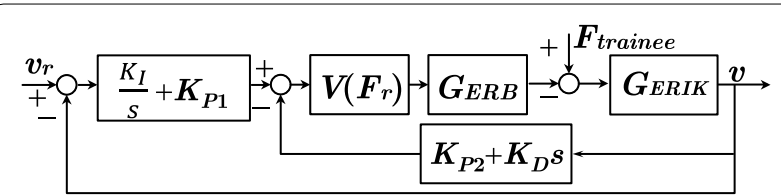

Fig. 13 Block diagram of the IPD controller for the isokinetic mode

\section{Control methods \\ The isotonic mode}

The isotonic mode enables isotonic exercise by loading a constant resistant (braking) force by the ERIK. The ER brake torque was calculated from the target value and Eq. (1) using feed-forward control.

\section{The isokinetic mode}

Real-time controlled resistance against the maximum effort of the trainee to slide the platform is generated for the isokinetic mode to keep the sliding velocity of the platform at the desired constant value.

The ER brake torque was controlled by a I-PD speed controller as shown in Fig. 13. Here, the velocity $v$, the target velocity $v_{r}$, the resistant force $F_{r}$, the model of the ER brake $G_{E R B}$, the model of the ERIK $G_{E R I K}$ and feedback gains $K_{I}$, $K_{P 1}, K_{P 2}$ and $K_{D}$ are used. The value of $v_{r}$ is decided by the trainer according to the condition of the trainee. The driving force for the platform by the trainee $F_{\text {trainee }}$ was treated as a disturbance. The speed controller using passive elements was empirically selected; the simple IP controller was avoided because the IP controller did not produce 


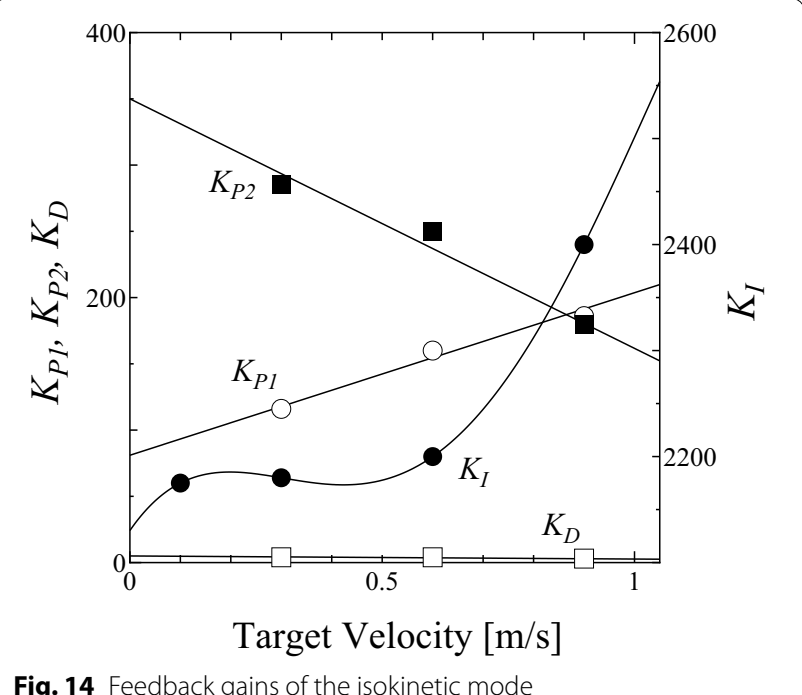

Fig. 14 Feedback gains of the isokinetic mode

appropriate results [4]. Thus, adding degrees of freedom to the IP controller for following the velocity and suppression of vibration, and the resistant force $F_{r}$ can be expressed as follows:

$$
\begin{gathered}
F_{r}=K_{I} \int\left(v_{r}-v\right) d t+K_{P 1}\left(v_{r}-v\right) \\
-K_{P 2} v-K_{D} \dot{v} \\
\text { if } F_{r}<0, \text { then } F_{r}=0 .
\end{gathered}
$$

The driving force for the platform depends on the trainee, and modeling a trainee's body is complex. For this reason, despite the platform's position being restricted to the external floor by the trainee's leg, the feedback gains were experimentally tuned, as shown in Fig. 14. The feedback gain $K_{P 2}$ contributed suppression of vibration of the platform's motion. Because the feedback gains cannot be treated as optimized, they could potentially be improved with other tuning methods.

\section{The initial resistance mode}

Because ACL injuries often occur at shallow knee bending, the initial resistance mode is expected to improve the posture control ability and prevent knee from injuries in shallow knee bending postures. Given the position of the platform $x$, the preset stroke length $x_{\max }$, the target force value $F_{r \max }$ shown in Fig. 9 and the base resistive force $F_{r b}$, $F_{r}$ can be expressed as follows:

$$
\begin{aligned}
& F_{r}=\left(1-\frac{x}{x_{\text {max }}}\right) F_{r \max } \\
& \text { if } F_{r}<F_{r b} \text { then } F_{r}=F_{r b} .
\end{aligned}
$$

In the current study, $x_{\max }=0.70 \mathrm{~m}$ and $F_{r b}=50 \mathrm{~N}$ were fixed. Using Eq. (1), $V$ was calculated and applied to the ER brake.

\section{The terminal resistance mode}

The terminal resistance mode can augment the activity of major muscles and the internal hip abduction moment with deep knee bend of the squatting leg: a sporting activity often require the posture. In this mode, $F_{r}$ can be written as same as in the previous section:

$$
\begin{aligned}
& F_{r}=\frac{x}{x_{\text {max }}} F_{\text {rmax }} \\
& \text { if } F_{r}<F_{r b} \text {, then } F_{r}=F_{r b} .
\end{aligned}
$$

\section{Experimental verification}

\section{The initial resistance mode}

This section describes the experimental verification of the ERIK and the controllers for the initial resistance modes using the measurement system, as shown in Fig. 10. The motor pulled the platform at a constant speed of approximately $0.20 \mathrm{~m} / \mathrm{s}$ while the ERIK controlled and loaded the resistance.

Figure 15 shows the results of trials for a target force of 50,100, 150 and $200 \mathrm{~N}$. The resistance force decreases according as Eq. (3) under $150 \mathrm{~N}$. In the case of the target force of $200 \mathrm{~N}$, the force in the starting phase is larger than the target value because of stretching of the wire and the stick-slip phenomenon of the ER brake.

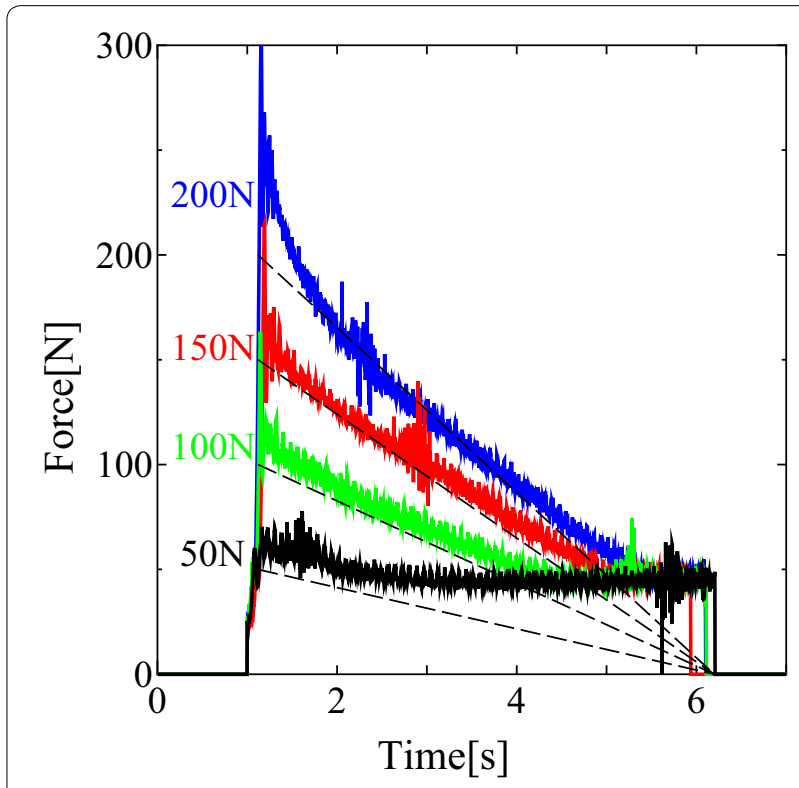

Fig. 15 Force response in initial resistance mode exercise 


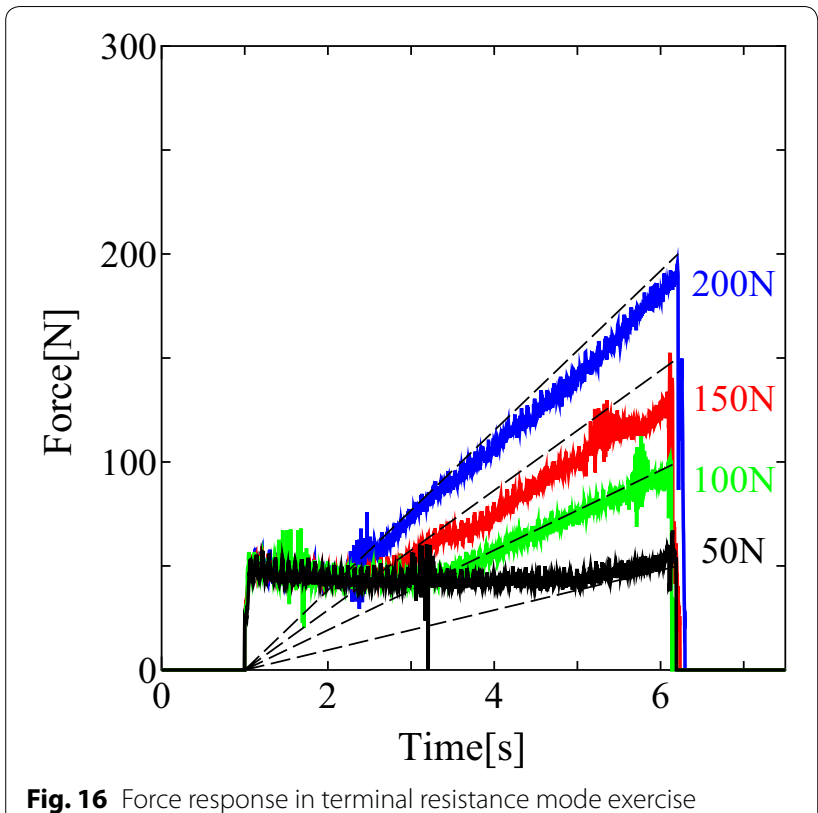

Fig. 16 Force response in terminal resistance mode exercise

\section{The terminal resistance mode}

Figure 16 shows the results of trials in the terminal resistance mode, under the same conditions described in the previous section.

The resistance forces increased according to Eq. (4).

\section{The isokinetic mode}

Figure 17 shows the results of trials in the isokinetic mode for target speeds of $0.30,0.60$ and $1.2 \mathrm{~m} / \mathrm{s}$. The platform was operated by one of the authors.

The results revealed that isokinetic motion was almost realized, although the response at $1.2 \mathrm{~m} / \mathrm{s}$ did not show a sufficient time period for evaluation while achieving the constant controlled speed.

The mean speed values during the constant speed shown in Fig. 18 indicated that the ERIK was able to follow the target velocity. The bullet shows the mean speed value for each reference speed. The coefficient of determination of the results from the dashed proportional line is 0.998 . The white circle shows the mean command force to the ERIK during the constant speed. This value would be expected to vary in each trainee, and could be used for evaluation of muscular function or motion function.

\section{EMG of a healthy subject}

This section describes the experimental verification of the ERIK and the controllers for the training modes using a healthy subject as a trainee. The trainee slid their left leg on the platform to the left while squatting down, then slid the same leg to the right while standing

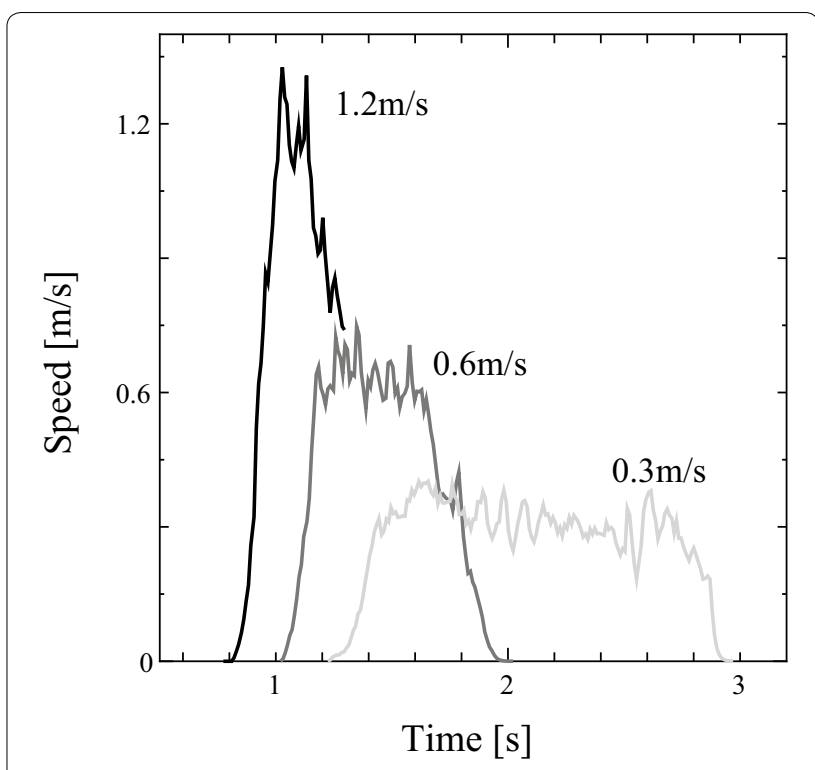

Fig. 17 Results of isokinetic exercises

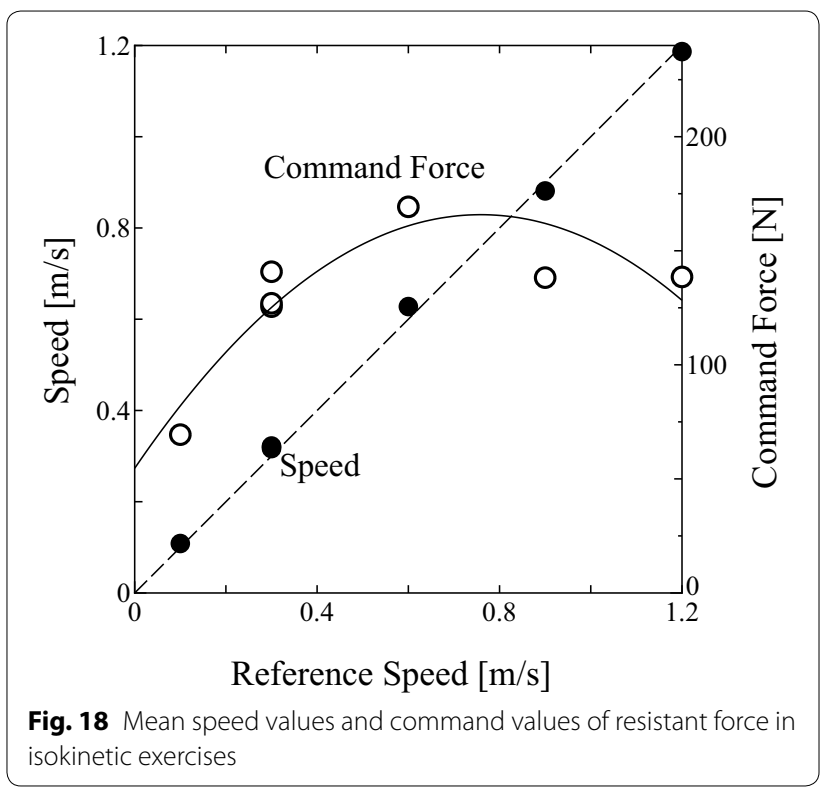

up. The subject was instructed to bend his right knee until about $80^{\circ}$, and practiced before experiments. In experiments, a bar was set in the front of the bending knee for a guide to control the knee bending angle. When sliding to the left, the resistance was loaded by the ERIK, while no resistance was loaded when sliding to the right. Because the particular muscles to be strengthened for preventing ACL injuries include the quadriceps femoris, gluteus medius (Gmed), gluteus maximus (Gmax), electromyograms (EMGs) of these 
muscles were measured. Vastus medialis (VM) was selected among the quadriceps femoris. For example, we conducted isotonic exercises for target forces of 0 and $120 \mathrm{~N}$ and a target speed of $0.25 \mathrm{~m} / \mathrm{s}$.

Root-mean-square (RMS) in 50 ms processed EMGs are shown in Figs. 19, 20 and 21. Each graph shows data during one squatting motion. Comparing with the EMG in the $0 \mathrm{~N}$ isotonic mode, exercises in the other modes required greater muscular activity, particularly

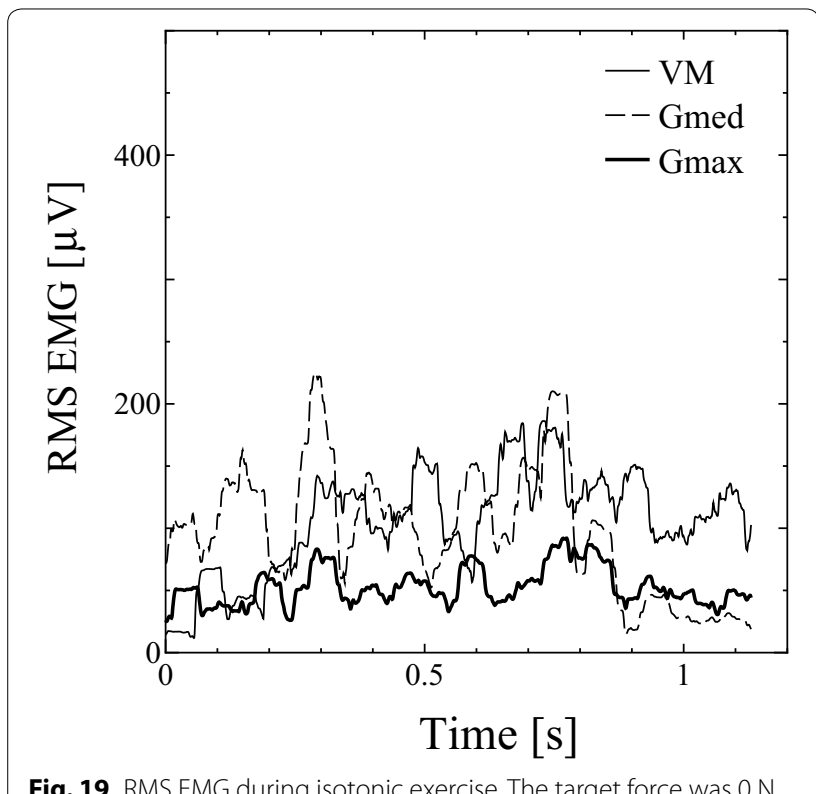

Fig. 19 RMS EMG during isotonic exercise. The target force was $0 \mathrm{~N}$

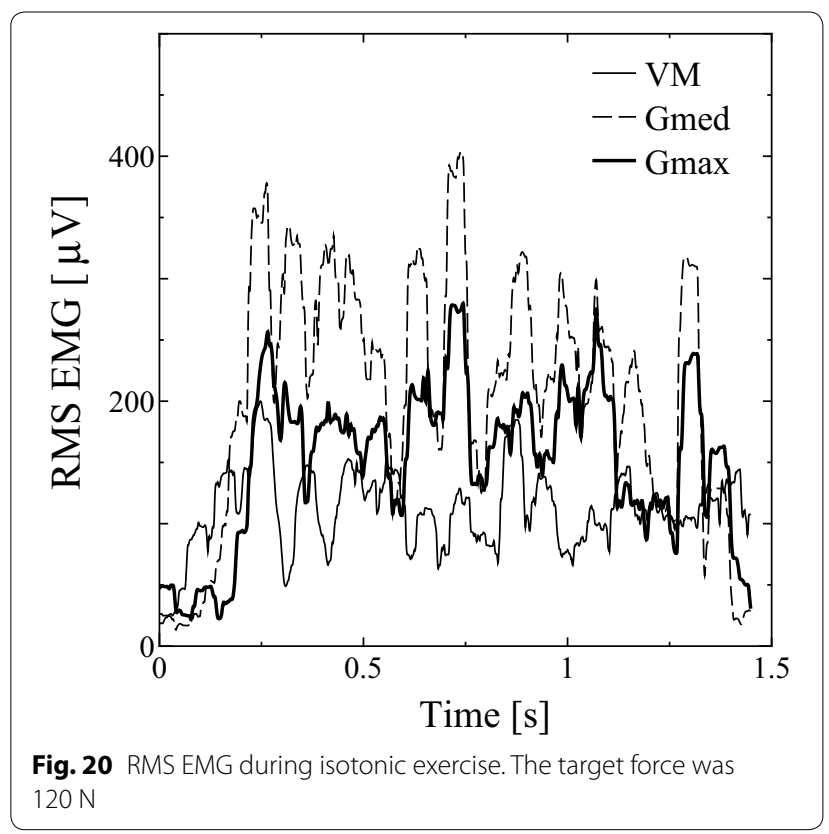

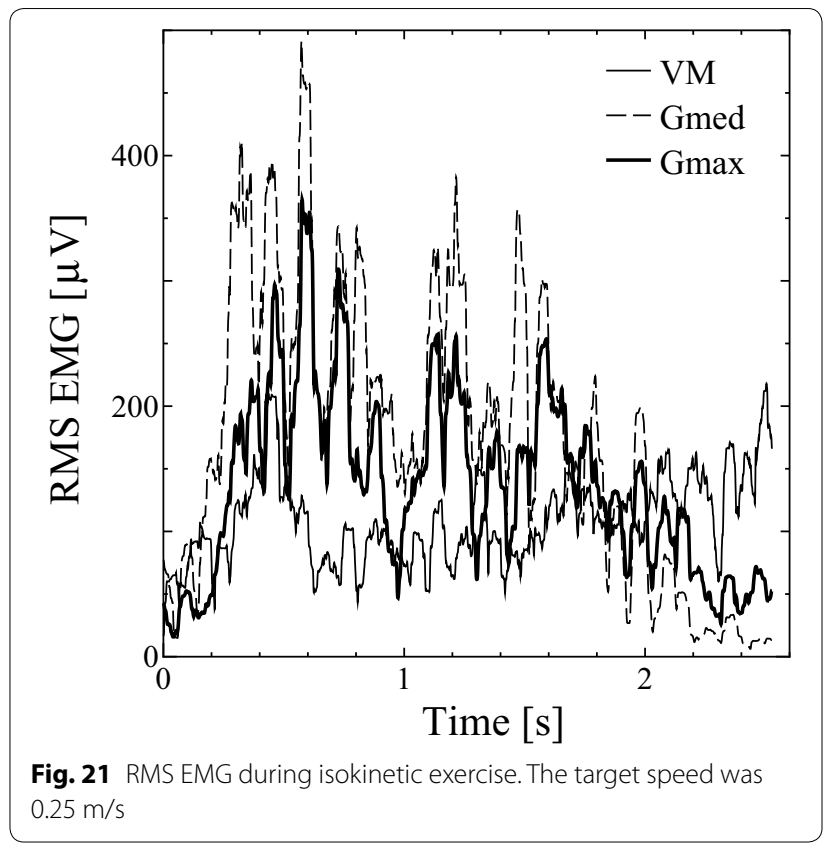

in Gmed and Gmax. Exercise in the isokinetic mode requires slower motion under this condition compared with isotonic exercises. However, isokinetic exercise places a greater load on the gluteal muscles than isotonic exercise. This indicates that the effects of using the ERIK were as planned.

\section{EMG of ACL reconstructed subject}

A male subject 1 year after an ACL reconstruction operation underwent tests using the ERIK. The subject was a professional soccer player in his twenties. The testing method was the same as that described in the previous section.

The results are shown in Figs. 22, 23 and 24. In the isotonic mode, the Gmed was loaded with a particularly large force from the opening of the exercise. Compared with the previous section, Gmax showed a slightly smaller but stable EMG during the period. In addition, the VM generally exhibited large EMG values. In the isokinetic mode, large forces are loaded on three muscles from the opening to the middle in spite of the moderate force loaded from the middle.

In addition, we conducted comparative tests using a conventional training device with a rubber band. Because the conventional device generates $80 \mathrm{~N}$ in the fully tensioned position of the platform, the results in the isokinetic mode of $80 \mathrm{~N}$ by the ERIK were also examined.

The results are shown in Figs. 25 and 26. Loads using the conventional device are shown as the terminal 

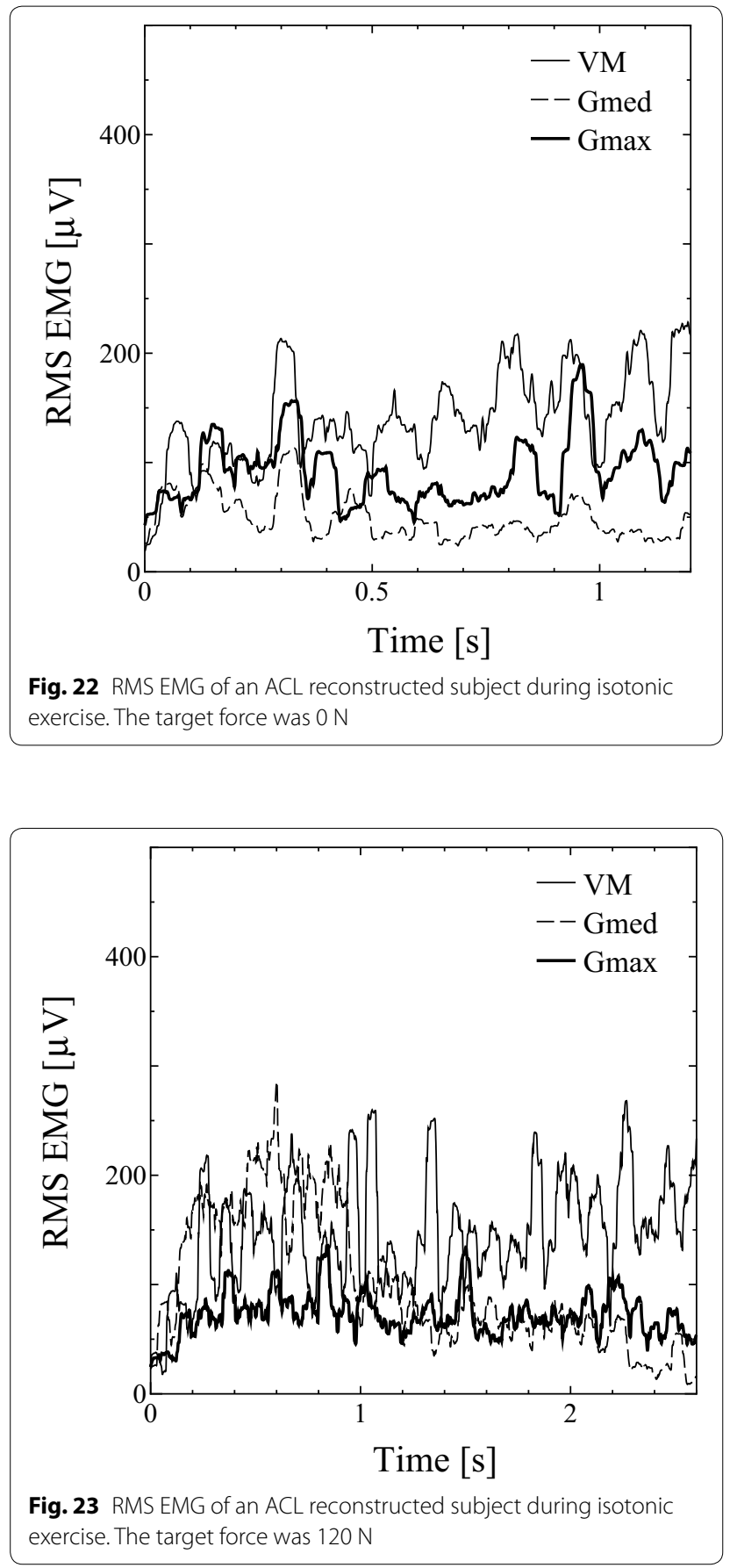

resistance mode. The EMG of the VM had a greater value from the middle compared with EMG during exercise with the ERIK. In contrast, Gmed exhibited moderate EMG signals when opening, followed by low values. Little force was loaded on Gmax during this period.

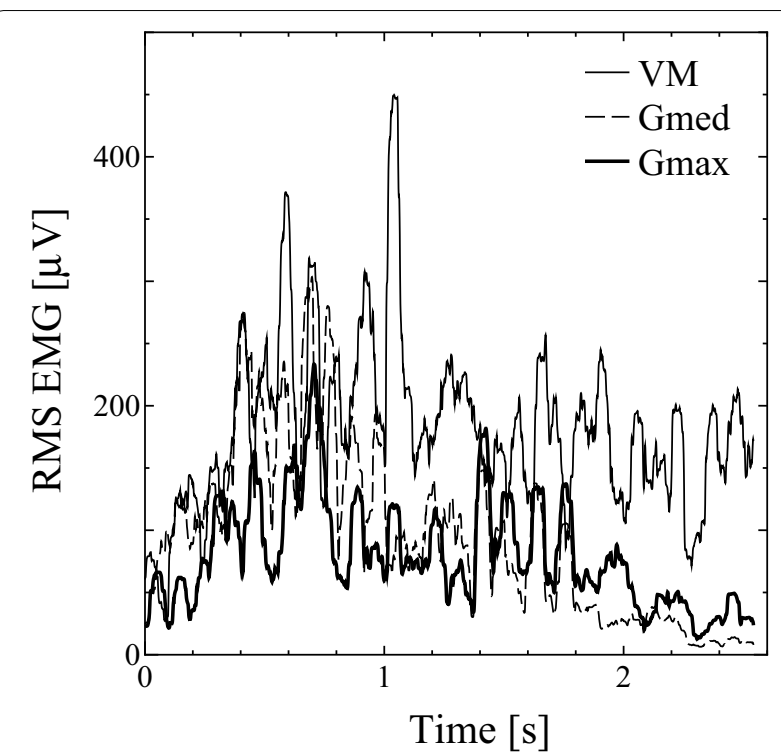

Fig. 24 RMS EMG of an ACL reconstructed subject during isokinetic exercise. The target speed was $0.25 \mathrm{~m} / \mathrm{s}$

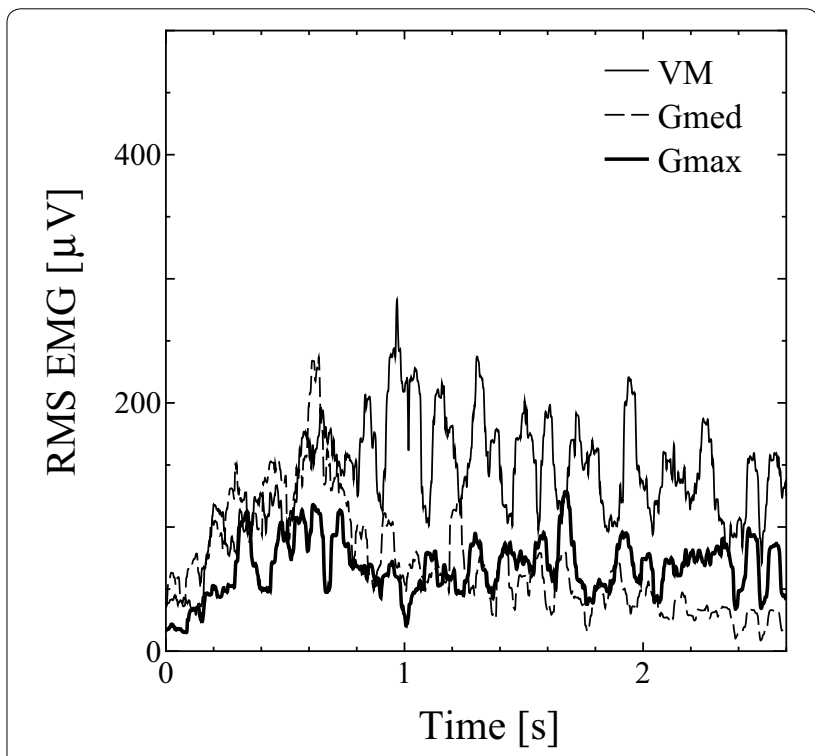

Fig. 25 RMS EMG of a subject with a reconstructed $A C L$ during isotonic exercise. The target force was $80 \mathrm{~N}$

\section{Discussions}

Excessive external knee valgus moment is a major factor in noncontact ACL injury [17, 18]. Gluteal muscle activity is important for preventing this, as well as excessive hip adduction [19]. Quadriceps femoris weakness is a common problem after injury and reconstruction of ACL $[20,21]$.

Proper isotonic mode and isokinetic mode exercise using the ERIK increased the load of Gmed and Gmax 


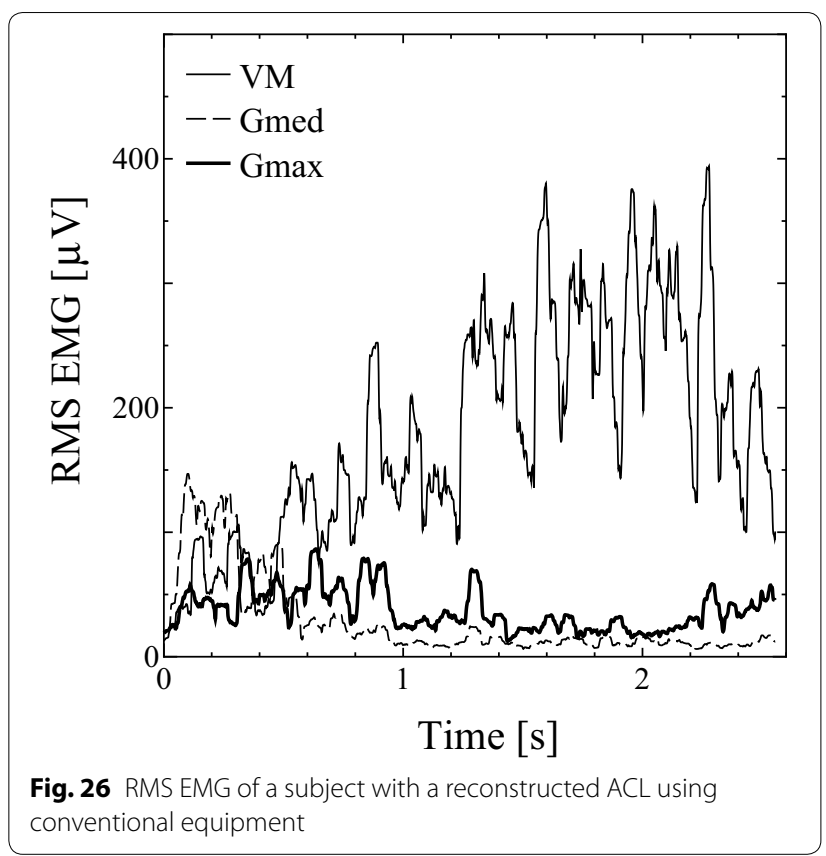

without reducing the load of VM, suggesting that these exercise modes may be useful for preventing ACL injury and recovering after ACL reconstruction. The results also indicate the ERIK was able to produce a more effective load on the gluteal muscles than the conventional device. Because ACL injuries often occur at shallow knee bending, the ability to apply specific loads on gluteal muscles from the opening of training is important for the prevention of ACL injury. These findings suggest that the ERIK provides an effective device for this type of training.

\section{Conclusion}

In the current study, we tested an isokinetic exercise device prototype, named the ERIK, for the lower limbs. The ERIK involves a resistive lateral/backward leg reach exercise in the CKC style, which applies load to the muscles in the standing position. In addition, the prototype uses an ER fluid brake to control the resistance. In the current study, we reported basic experimental results corresponding to four training modes. The isokinetic exercise mode was verified using electromyogram data, in which a large load was effectively applied to the gluteal muscles while protecting the ACL.

It should be noted that a problem remains with evaluation during isokinetic mode training of a specific duration. To address this difficulty, Also we plan to develop a displaying system set of evaluation and training conditions methods to provide helpful feedback to the trainee.

\section{Authors' contributions}

KK contributed to the conception and design of the ERIK, data collection, analysis and interpretation, and drafting the article. YK contributed to conception of the work and EMG data collection, analysis and interpretation. MK contributed to conception of the work and EMG data collection. Al designed and built the ERIK, including the ER brake. TT, KS, TM, HM and TO contributed to design of the measurement system and critical revision of the article. All authors read and approved the final manuscript.

\section{Author details}

${ }^{1}$ Faculty of Engineering, Toyama Prefectural University, 5180 Kurokawa, Imizu, Toyama 939-0398, Japan. ${ }^{2}$ Department of Rehabilitation, Osaka University Hospital, 2-15, Yamadaoka, Suita, Osaka 565-0871, Japan. ${ }^{3}$ Faculty of Biomedical Engineering, Osaka Electro-Communication University, 1130-70, Kiyotaki, Shijonawate, Osaka 575-0063, Japan. ${ }^{4}$ ER-tec Co., 2-1-31, Sakuragaoka, Minoh, Osaka 562-0046, Japan.

\section{Acknowledgements}

This work was supported by JSPS KAKENHI Grant Numbers 22500574, 25282192 and $17 \mathrm{H} 02135$. The authors wish to thank Mr. Y. Yamamoto, a former graduate student at Toyama Prefectural University, for help conducting the experiments.

\section{Competing interests}

A. Inoue is the CEO of ER-tec Co., Japan, a developer of the ER fluid.

\section{Ethics approval and consent to participate}

Experiments with subjects in this paper were approved by the research ethics committee of each organization (Toyama Prefectural University: No. H27-4, Osaka University Hospital: No.11527). All participants gave fully informed consent prior to testing.

\section{Publisher's Note}

Springer Nature remains neutral with regard to jurisdictional claims in published maps and institutional affiliations.

Received: 30 January 2018 Accepted: 29 May 2018

Published online: 04 June 2018

\section{References}

1. Japanese Orthopaedic Association (ed) (2012) Clinical practice guideline on the management of anterior cruciate ligament injury of the knee, pp 5-6. Nankodo, Tokyo (in Japanese)

2. Noyes FR, Barber-Westin SD (2014) Neuromuscular retraining intervention programs: do they reduce noncontact anterior cruciate ligament injury rates in adolescent female athletes? Arthroscopy 30(2):245-255

3. Kimura Y, Koyanagi M, Tanaka N, Ogawa T, Nakae N (2010) Motion analysis of the support leg during lateral leg reach exercise. Jpn J Clin Biomech 31:445-452 (in Japanese)

4. Koyanagi K, Kimura Y, Koyanagi M, Inoue A, Motoyoshi T, Masuta H, Oshima T (2014) Development of an isokinetic exercise equipment for the lower limb: ERIK. In: Proceedings of the 12th international conference on motion and vibration control, pp 2-13

5. Kimura Y, Koyanagi M, Mukai K, Nakae N, Tada S, Satoda Y, Tanaka N, Sato M, Oda K (2013) Motion analysis of the support leg during lateral leg reach with a constant resistive force. Jpn J Clin Biomech 34:239-244 (in Japanese)

6. Yamamoto Y, Koyanagi K, Kimura Y, Koyanagi M, Inoue A, Motoyoshi T, Masuta H, Oshima T (2014) Verification of device type of strength training machine using ER fluid brake. In: Proceedings of the 2014 IEEE/SICE international symposium on system integration, pp 779-784

7. Cotte T, Ferret JM (2003) Comparative study of two isokinetics dynamometers: CYBEX NORM vs CON-TREX MJ. Isokinet Exerc Sci 11:37-43

8. Nugent EP, Snodgrass SJ, Callister R (2015) The effect of velocity and familiarisation on the reproducibility of isokinetic dynamometry. Isokinet Exerc Sci 23(3):205-214

9. English KL, Hackney KJ, De Witt JK, Ploutz-Snyder RJ, Goetchius EL, PloutzSnyder LL (2013) A ground-based comparison of the muscle atrophy 
research and exercise system (MARES) and a commercially available isokinetic dynamometer. Acta Astronaut 92(1):3-9

10. Matsushita Electric Works Co., Ltd. (2002) Kinryoku, Kunren Hyouka Souchi (Japanese). JP 2002-126122A

11. Kimura Y, Koyanagi M, Nakae N, Tanaka N, Sato M (2009) Motion analysis of the support leg during backward leg reach exercise. Jpn J Clin Biomech 30:451-456 (in Japanese)

12. Furusho J, Kikuchi T, Oda K (2002) Isokinetic exercise training and evaluation system using particle-type ER fluid. Trans Jpn Soci Mech Eng (C) 68(672):2418-2424 (in Japanese)

13. Oda K, Kikuchi T, Oyama Y, Furusho J (2010) Isokinetic exercise machine with MR fluid brake. J Jpn Soc Exp Mech 10(2):176-181 (in Japanese)

14. Adams D, Johnston $L$ (2001) Industrial benefits of ERF-technology (a development report from the industry). In: Proc. of the eighth int. conf. on electro-rheological fluids and magneto-rheological suspensions, pp 37-42. World Scientific, Singapore

15. Koyanagi K, Furusho J (2005) Progress of passive-type force display system with ER fluid devices. Int J Mod Phys B 19(7-9):1641-1647

16. Nakano H, Nakano M (2014) Evaluation and training system of muscle strength for leg rehabilitation utilizing an MR fluid active loading machine. In: Yoshida K, Tadokoro S (eds) Field and service robotics, vol 92. Springer tracts in advanced robotics. Springer, Berlin, pp 191-203

17. Hewett TE, Myer GD, Ford KR, Heidt RS, Colosimo AJ, McLean SG, Van den Bogert AJ, Paterno MV, Succop P (2005) Biomechanical measures of neuromuscular control and valgus loading of the knee predict anterior cruciate ligament injury risk in female athletes. Am J Sports Med 33(4):492-501

18. Koga H, Nakamae A, Shima Y, Iwasa J, Myklebust G, Engebretsen L, Bahr $R$, Krosshaug $T$ (2010) Mechanisms for noncontact anterior cruciate ligament injuries: knee joint kinematics in 10 injury situations from female team handball and basketball. Am J Sports Med 38(11):2218-2225

19. Zazulak BT, Ponce PL, Straub SJ, Medvecky MJ, Avedisian L, Hewett TE (2005) Gender comparison of hip muscle activity during single-leg landing. J Orthop Sports Phys Ther 35(5):292-299

20. Shino K, Inoue M, Horibe S, Hamada M, Ono K (1990) Reconstruction of the anterior cruciate ligament using allogeneic tendon: long-term followup. Am J Sports Med 18(5):457-465

21. Rosenberg TD, Franklin JL, Baldwin GN, Nelson KA (1992) Extensor mechanism function after patellar tendon graft harvest for anterior cruciate ligament reconstruction. Am J Sports Med 20(5):519-526

\section{Submit your manuscript to a SpringerOpen ${ }^{\odot}$ journal and benefit from:}

- Convenient online submission

- Rigorous peer review

- Open access: articles freely available online

- High visibility within the field

- Retaining the copyright to your article

Submit your next manuscript at $\boldsymbol{\nabla}$ springeropen.com 